\title{
KONCEPTUALNI OKVIR - LIDERSTVO
}

\section{LEADERSHIP - CONCEPTUAL FRAMEWORK}

\author{
Snežana Trmčić \\ Fakultet za menadžment malih i srednjih preduzeća, Venizelosova 31, Beograd, Republika Srbija

\section{Ozrislava Milinković} \\ Fakultet za menadžment malih i srednjih preduzeća, Venizelosova 31, Beograd, Republika Srbija

\section{Marko Trmčić} \\ Fakultet za menadžment malih i srednjih preduzeća, Venizelosova 31, Beograd, Republika Srbija
}

\section{(C) MESTE NGO}

\section{Sažetak:}

Globalna konkurencija povezana sa potrebom kupaca za povećanim kvalitetom proizvoda i usluga, pojačava potrebu za fleksibilnošću i kreativnošću od strane organizacije. Slab menadžment i manjak liderstva su veoma često okrivljeni za probleme sa kojima se suočavaju organizacije širom sveta. Mnoge organizacije se restrukturiraju i uvode nove principe poslovanja da bi ostale konkurentne na svetskom tržištu. Najviše promena uvedeno je u načinu na koji zaposleni obavljaju posao. Zaposleni su sve obrazovaniji pa mlađi kadar u organizaciji očekuje veći stepen autonomije i učestvovanja u odlučivanju. Zaposleni se treniraju iz raznih oblasti biznisa i od njih se očekuje da donose samostalne odluke. Oni očekuju brza unapređenja, izazovne mogućnosti koje će im pružiti priliku da steknu vredno iskustvo, trening i balans između privatnog i poslovnog života. Sa povećanom upotrebom timova u organizaciji, mnoge od tradicionalnih uloga lidera se menjaju. Timovi su dizajnirani da upotpune individualne osobine zaposlenih. Samorukovođeni timovi su zaslužni za kontinuiranu procenu i unapređenje proizvoda kao i za dizajn njihovog rada i svih drugih radnih procesa koji na njih utiču. Lideri su često izabrani od strane članova tima i svaki član je odgovoran za sopstvene akcije $i$ odluke. Ove promene u načinu rukovođenja, kao i poslovanja u mnogim organizacijama pomeraju fokus sa lidera na zaposlene. Cilj rada je prikaz analiza modela liderstva, i njihove uloge po istoimenom konceptu.

\section{Ključne reči:}

liderstvo, super liderstvo, samo liderstvo, transakciono liderstvo, transformaciono liderstvo

Adresa autora zaduženog za korespodenciju:

Snežana Trmčić

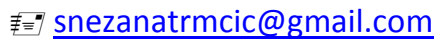




\begin{abstract}
:
Global competition connected with customers' demand for quality increase of products and services is intensifying the need for flexibility and creativity of the organization. Poor management and lack of leadership are very often blamed for problems faced by the organizations all over the world. Many organizations are restructuring and introducing new business principles in order to stay competitive on the world market. Most changes have been introduced in the manner in which employees perform work. Employees are becoming more educated which leads to the result that younger members of the staff in organizations are expecting higher level of autonomy and participation in decision making. Employees are trained in various fields of business and they are expected to independently make decisions. They expect fast career advancement, challenging possibilities which will give them an opportunity to gain valuable experience through training and balance between private and professional life. With the increased use of teams in the organization, many of the traditional roles of leaders are changing. The teams are designed to complement employees' individual traits. Self-managed teams are deserved for continues assessment and improvement of the products as well as for the design of their work and all other work processes that affect them. Leaders are very often elected by the members of the team and each member is responsible for their own actions and decisions. These changes in management and operations in many organizations are shifting focus from leaders to employees. Purpose of this article is the analysis of leadership models and their role in the organizations.
\end{abstract}

\title{
Keywords:
}

leadership, super-leadership, self-leadership, transactional-leadership, transformational-leadership

\section{Uvod}

Pod pritiskom da se postigne bolji kvalitet, konstantnim poboljšanjem kao i pritiskom za korišćenjem timova organizacije se ubrzano menjaju. Rezultat toga je da se mnoge tradicionalne uloge i funkcije lidera moraju delegirati sledbenicima. Fokusiranost na kvalitet i timski rad $u$ svim aspektima procesa donošenja odluka i implementacija prisiljava nas da razmislimo o očekivanjima i zahtevima za lidere. Efektivni timski lideri nisu uvek u kontroli nad grupom. Na primer zaposleni u tradicionalnoj organizaciji su odgovorni samo za produkciju dok planiranje, vođenje i kontrola kao i postizanje rezultata je odgovornost menadžera. Ipak veliki broj organizacija polako premešta odgovornosti menadžera na zaposlene jer se na taj način rasterećuje menadžer i omogućava mu se fokusiranje na pružanje podrške zaposlenima dok se zaposleni osamostaljuju a samim time i dodatno motivišu. U novije vreme od menadžera se očekuje da obezbedi viziju, obezbedi sve potrebne resurse pruži podršku i skloni se sa puta zaposlenih. Za uzvrat zaposleni uče o strategijskim i finansijskim pitanjima koji su vezani za njihov posao, planiraju svoje aktivnosti postavljaju ciljeve proizvodnje i preuzimaju odgovornost za svoje rezultate. U skladu sa ovim promenama koncept liderstva se menjao od transakcionog, transformacionog do super i samo liderstva.

\subsection{Faktori koji podstiču promene}

Brojne eksterni i interni organizacioni faktori podstiču promene u organizacijama i menjanju tradicionalne uloge lidera i menadžera. Političke promene širom sveta vode ka većoj otvorenosti i demokratiji. Ove političke promene menjaju ideje o tome šta je to primereno liderstvo.

Padom Sovjetskog Saveza i krajem dvadesetog veka u svetu je počela sve veća primena demokratskih principa čiji je cilj bio podela moći. $U$ SAD javnost nastavlja da preispituje i zahteva otvorenost povodom raznih afera. Političari su prisiljeni da razotkriju veći deo njihove prošlosti i opravdaju se javnosti za skoro sve donesene odluke. Zajednice imaju povećane zahteve za učestvovanjem u odlukama koje se tiču zdravstvenog sistema, škola i životne sredine.

Sa povećanjem globalne i lokalne konkurencije, kompleksne i brzo promenljive tehnologije, brojne organizacije se bore za opstanak. Mnogi su primorani da preispitaju način na koji obezbeđuju dobra ili usluge za svoje potrošače kao i sve 
osnovne principe svog poslovanja. Bill Ford, Jr., glavni izvršni direktor Ford Motors-a, je ne samo pobornik zaštite prirode već je pristao da održi govor na konferenciji „Greenpeace“-a kao i da redovno dolazi na sastanke sindikata noseći bedž na kome piše da on mrzi filozofiju "oni protiv nas“. On ostaje blizu svojih zaposlenih, redovno se hrani u Ford kafeteriji i zainteresovan je u učestvovanju u hokejaškoj ligi svojih zaposlenih (Truby, 2003).

Globalna konkurencija povezana sa potrebom kupaca za povećanim kvalitetom proizvoda i usluga pojačava potrebu za fleksibilnošću i kreativnošću od strane organizacije. Slab menadžment i manjak liderstva su veoma često okrivljeni za probleme sa kojima se suočavaju organizacije širom sveta. Mnoge organizacije se restrukturiraju i uvode nove principe poslovanja da bi ostale konkurentne na svetskom tržištu. Najviše promena uvedeno je u načinu na koji zaposleni obavljaju posao. Zaposleni su sve obrazovaniji pa mlađi kadar u organizaciji očekuje veći stepen autonomije i učestvovanju u odlučivanju. Oni očekuju brza unapređenja, izazovne mogućnosti koje će im pružiti priliku da steknu vredno iskustvo, trening i balans između privatnog i poslovnog života. Sve ove promene vode do promene uloge lidera u organizaciji.

Povećanje poslova u uslužnom sektoru na uštrb tradicionalnih proizvodnih poslova stavlja zaposlene u direktni kontakt sa kupcima. Ova promena zahteva promene $u$ načinu na koji su zaposleni trenirani. Ova promena takođe znači da zaposleni moraju da koriste procenjivanje i da donose brze odluke koje su ranije bile rezervisane samo za menadžment. Kao rezultat ovog pritiska za promenom mnoge organizacije počinju da preispituju svoje poslovanje i smišljaju načine da odgovore na sve veće promene na tržištu nastale usled globalizacije. Globalizacija uvodi faktor novih kultura sa kojima se zaposleni susreću različitih sistema vrednosti i td. Ted Childs, IBM-ov predsednik globalne mreže redovno govori svojim zaposlenima: "Moraćete da prodajete ljudima koji su različiti od vas, i kupujete od ljudi koji su različiti od vas, upravljate ljudima koji su različiti od vas u svakom pogledu....tako se u ovoj kompaniji posluje. Ako vam to ne odgovara odmah odustanite." (Swan, 2000, p. 260).

\section{$1.2 \quad$ Lideri i delegiranje}

Delegacija se razlikuje od prostog učestvovanja zaposlenih iako je mnogi menadžeri smatraju aspektom participacije. Mnogi menadžeri definišu sebe kao participativne menadžere ako delegiraju zadatke svojim sledbenicima. lako ova praksa može dovesti do toga da sledbenici više učestvuju u donošenju odluka, primaran cilj delegacije je jednostavno pomaganje lideru sa često vrlo velikim obimom posla. U svojoj osnovnoj formi delegacija znači prepuštanje zadatka nekome drugom da ga izvrši. U svojoj složenijoj formi delegacija liči na participativni menadžment.

\subsection{Korist od delegiranja}

Delegiranje zadataka podređenima dobija na značaju usled povećanja obima posla menadžera. Usled globalizacije brisanja granica i širenja poslovanja menadžeri imaju više zaposlenih i veću teritoriju koju pokrivaju; menadžeri proizvodnje sada imaju dva puta više zaposlenih da nadgledaju; menadžeri prodaje imaju dva puta više teritorije da pokriju u nastojanju postizanja veće efektivnosti. Zbog svega navedenog mnoge organizacije testiraju uvođenje timova u svoju organizacionu strukturu. Trenutno delegacija je osnovno sredstvo uspeha lidera. Beneficije od delegiranja su sledeće:

- daje više vremena lideru da se pozabavi strateškim aktivnostima;

- daje mogućnost zaposlenima da uče i razvijaju se;

- daje mogućnost zaposelnima da budu uključeni u zadatak;

- povećava motivaciju i satisfakciju zaposlenih.

Pored toga što daje više vremena lideru da se bavi strateškim pitanjima, delegiranje omogućava podređenima da se oprobaju na novim zadacima nauče nove veštine a samim tim izbegava se rutina i povećava nivo njihove motivisanosti kao i lična satisfakcija. Kada zaposleni izvršavaju nove zadatke lideri imaju mogućnost da ih posmatraju i skupljaju informacije o njihovom učinku i sposobnostima. Ove informacije lideri mogu iskoristiti da bi se zaposleni dalje razvijali i pripremali za unapređenje. Delegacija je jedan od alata koji lideri koriste da planiraju razvoj organizacije i odabiraju naslednike postojećih lidera na svim nivoima kompanije. Zaposleni koji 
konstantno imaju dobre rezultate i voljni su da preuzmu više odgovornosti na sebe mogu biti budući lideri u organizaciji. Bez mogućnosti da se razvijaju izvan okvira svog posla nema načina da se izvrši procena njihove sposobnosti i potencijala za unapređenje. Još jedna prednost delegacije je veća povezanost zaposlenih prema poslu kao i posvećenost.

Studija o participativnom menadžmentu i obogaćenja posla zaposlenih (Hackman \& Oldham, 1980) jasno govori da zaposleni koji su ambiciozni i zainteresovani za rast i razvoj se vrlo brzo osećaju demotivisano ako nemaju mogućnost da učestvuju u novim i izazovnim zadacima. Delegacija takvih zadataka zaposlenima povećava nivo njihove motivacije kao i posvećenost organizaciji. Efektivno liderstvo zahteva više delegacije. Lideri moraju da budu jasni oko toga šta zahtevaju od zaposlenih moraju da im pružaju podršku dok obavljaju zadatak. Podrška može da znači obaveštavanje članova odeljenja i drugih izvan odeljenja da je zadatak delegiran. Podrška takođe može da znači obezbeđivanje odgovarajućeg treninga i resursa za uspešno izvršavanje zadatka kao i redovna kontrola i pojašnjavanje očekivanih rezultata (Forster, 2004). Ukoliko nema konstantne kontrole zaposleni vrlo lako mogu da naprave grešku i donesu odluku koja nije u skladu sa ciljevima lidera i kompanije.

Ipak delegiranje nije poželjno kada su u pitanju privatni problemi. Ukoliko se odeljenje ili organizacija ne restrukturiraju u samokontrolišuće timove koji imaju odgovornost da sami ocenjuju učinak i daju povratnu informaciju i dalje je pitanje participativnog menadžmenta dužnost lidera. $\mathrm{Na}$ primer bilo bi nedolično za menadžera da pitanje disciplinovanja zaposlenog koji kasni prepušta svom potčinjenom ili da očekuje od njih da nadgledaju kontrolišu i procenjuju učinak pojedinca.

Lideri moraju pažljivo odabrati kome da delegiraju zadatke. Najlakši izbor za većinu menadžera je da delegiraju zadatak nekolicini poverljivih ljudi za koje znaju da će dobro obaviti zadatak. lako je takav stav logičan i efektivan, bar na kratke staze lideri moraju pažljivo da odaberu pojedince koji su, pored toga što su pokazali potencijal $i$ poseduju neophodne veštine za izvršenje poverenog zadatka, odlučni i motivisani da prihvate nove izazove. Sledbenik koji je sposoban i odlučan ali nije dobro izvršio jedan od poverenih zadataka i dalje može da bude dobar izbor ali možda ne bude uzet $u$ obzir ako se lideri po inerciji oslanjaju samo na nekolicinu zaposlenih. Delegiranjem zadataka raznovrsnoj grupi zaposlenih lider dobija bolji uvid u mogućnosti i potencijal svog tima ili odeljenja. Kreiranje klime koja toleriše greške $\mathrm{i}$ ohrabrivanje kontinuiranog treninga je esencijalno za uspeh lidera.

\subsection{Razlozi zbog kojih lideri ne delegiraju}

Određene okolnosti opravdavaju nevoljnost lidera da delegiraju. $U$ nekim slučajevima sledbenici nisu spremni da preuzmu veću odgovornost i zadatke na sebe. To se obično dešava u slučajevima kada su već previše opterećeni ili imaju visoko specijalizovane poslove tako da im se novi zadaci ne mogu delegirati. Takve situacije su retke i dobre strane delegacije nadmašuju loše. Najčešće korišćeni argumenti protiv delegacije prikazani su u tabeli 1.

Tabela 1 Izgovori za i protiv delegiranja

\begin{tabular}{|l|l|}
\hline $\begin{array}{l}\text { Izgovori za } \\
\text { nedelegiranje }\end{array}$ & Kontra argumenti \\
\hline $\begin{array}{l}\text { Moji sledbenici nisu } \\
\text { spremni. }\end{array}$ & $\begin{array}{l}\text { Liderov posao je da pripremi } \\
\text { sledbenike za nove zadatke i } \\
\text { izazove. }\end{array}$ \\
\hline $\begin{array}{l}\text { Sledbenici nemaju } \\
\text { potrebna znanja i } \\
\text { veštine. }\end{array}$ & $\begin{array}{l}\text { Liderov posao je da trenira } \\
\text { sledbenike i obuči in za nove } \\
\text { zadatke i izazove. }\end{array}$ \\
\hline $\begin{array}{l}\text { Osećam se neprijatno } \\
\text { da tražim od } \\
\text { sledbenika da } \\
\text { preuzmu deo mojih } \\
\text { dužnosti. }\end{array}$ & $\begin{array}{l}\text { Samo se par zadataka ne } \\
\text { može delegirati. }\end{array}$ \\
\hline $\begin{array}{l}\text { Ja mogu brže i bolje } \\
\text { sam završiti posao. }\end{array}$ & $\begin{array}{l}\text { Odvajanjem vremena za } \\
\text { trening zaposlenih oslobađa } \\
\text { slobodno vreme na duže } \\
\text { staze. }\end{array}$ \\
\hline $\begin{array}{l}\text { Ako moj zaposleni } \\
\text { napravi grešku, ja } \\
\text { sam kriv. }\end{array}$ & $\begin{array}{l}\text { Tolerisanje grešaka i } \\
\text { eksperimentisanje je } \\
\text { esencijalno za razvoj i } \\
\text { učenje. }\end{array}$ \\
\hline Moj nadređeni može & $\begin{array}{l}\text { Delegiranje omogućava sledisenici moraju } \\
\text { naučiti da balansiraju sa } \\
\text { teretom obaveza tako što će } \\
\text { utvrditi prioritete. }\end{array}$ \\
\hline
\end{tabular}


pomisliti da ne radim i vremena za strateške ne trudim se dovoljno. aktivnosti.

Gledanjem šire slike i uzimajući u obzir liderovu ličnu efektivnost kao i razvoj zaposlenih mnogi od gore navedenih izgovora prestaju da važe. Efektivna delegacija zahteva trud vreme i resurse ali omogućava lideru da se fokusira na strategijska pitanja umesto da se bavi svakodnevnim problemima. Ipak ličnost samog lidera kao i njegov karakter mogu sprečiti lidera da delegira. Potreba za kontrolom kao i strah od gubljenja iste su faktori koji utiču i sprečavaju lidera da delegira. Potreba za konstantnom moći može sprečiti lidere da delegira baš kao i strah da zaposleni mogu postati konkurencija lideru (McClelland, 1975).

\section{Timovi i liderstvo}

Upotreba timova u USA i drugim zemljama je jedan od glavnih trendova sa kraja dvadesetog veka. Mnoge organizacije su uvrstile timove u permanentni deo ako ne i kamen temeljac svojih organizacionih struktura. Timovi kreiraju formalnu strukturu kroz koju učestvovanje u donošenju odluka može biti ostvareno. Upotreba timova u USA i drugim zapadnim organizacijama je u velikoj meri bilo inspirisano Japanskim ekonomskim uspehom i korišćenjem participativnog menadžmenta (Nahavandi \& Aranda, 1994). lako timovi nisu uvek uspešni i često predstavljaju pozamašan izazov za organizaciju veliki broj organizacija nastavlja da koristi timove kao alat za povećavanjem nivoa kreativnosti, inovativnosti i kvaliteta.

\subsection{Karakteristike timova}

Mnogo godina organizacija je koristila grupe da postigne svoje ciljeve ipak koncept korišćenja timova kao centralnog elementa procesa donošenja odluka i učinka su novija pojava.

Jedna od najupečatljivijih odlika tima jeste potpuna posvećenost članova zajedničkom cilju i pristupu koji u većini slučajeva sami odaberu. Članovi moraju da se slože da je cilj tima vredan truda i napora kao i oko opšteg pristupu ispunjenja tog cilja. Takav dogovor obezbeđuje viziju i služi kao izvor motivacije članovima tima da postignu zacrtani cilj. Da bi uspeo članovi tima moraju da se osećaju odgovorno jedan za drugog kao i za organizaciju i rezultate njihovog rada. Treća karakteristika tima je kultura bazirana na poverenju i saradnji. Članovi tima su spremni da sarađuju prave kompromise da bi dostigli zajednički cilj.

Tabela 2 Razlike između grupa i timova

\begin{tabular}{|l|l|}
\hline GRUPE & TIMOVI \\
\hline $\begin{array}{l}\text { Svi članovi rade } \\
\text { na ostvarenju } \\
\text { zajedničkog cilja. }\end{array}$ & $\begin{array}{l}\text { Svi članovi rade su potpuno } \\
\text { posvećeni ostvarenju zajedničkog } \\
\text { cilja kao i misiji koju su razvili }\end{array}$ \\
\hline $\begin{array}{l}\text { Menadžer je } \\
\text { odgovoran za } \\
\text { članove grupe. }\end{array}$ & $\begin{array}{l}\text { Sve članovi su odgovorni jedan za } \\
\text { drugog. }\end{array}$ \\
\hline $\begin{array}{l}\text { Članovi nemaju } \\
\text { jasnu stabilnu } \\
\text { strukturu i konflikti } \\
\text { često izbijaju. }\end{array}$ & $\begin{array}{l}\text { Članovi tima veruju jedan drugom i } \\
\text { kultura ohrabruje saradnju. }\end{array}$ \\
\hline $\begin{array}{l}\text { Liderstvo je } \\
\text { dodeljeno jednoj } \\
\text { osobi. }\end{array}$ & Svi članovi učestvuju u liderstvu. \\
\hline $\begin{array}{l}\text { Grupa može da } \\
\text { ostvari cilj. }\end{array}$ & Članovi tima ostvaruju sinergiju. \\
\hline
\end{tabular}

Pozitivna klima u timu ne znači da nema konflikta među članovima. Konflikt može da popravi kreativnost u timu kao i celokupni učinak ako se sa njim barata konstruktivno. Povezano sa timskom kulturom je i zajedničko liderstvo. Dok u grupi postoji jedan lider u timu se liderstvo deli među članovima. Timovi dele sinergiju što znači da tim kao celina može da postigne više nego pojedinac zasebno. Kombinovanje napora, znanja i veština često rezultuje većim učinkom a organizaciji mogu doneti smanjenje troškova zbog manje potrebe za kontrolom, veću posvećenost zaposlenih i veću fleksibilnost (Cordery, 2004).

\subsection{Samokontrolišući timovi}

Uloga tradicionalnih lidera i menadžera je da obezbede kontrolu i komandu, lider u timu ima ulogu da potpomogne procese i obezbedi podršku timu. Lider postavlja generalni pravac i ciljeve dok članovi tima donose sve odluke i implementiraju in. Ova nova uloga je karakteristična za samokontrolišuće timove koji se sastoje od zaposlenih sa potpunom menadžerskom kontrolom za svoj rad. Organizacije, kao što su: "Toyota", "General Foods“, i „Procter \& Gamble“, decenijama 
koriste samokontrolišuće timove (Fisher, 1993). Samokontrolišući timovi ispoljavaju sledeće karakteristike :

- Moć da sami organizuju svoj posao. Oni mogu da postave ciljeve planiraju resurse, prate kvalitet i implementiraju odluke

- Članovi poseduju različita znanja i veštine. Članovi tima mogu da budu iz marketinga, finansija, proizvodnje, dizajna itd. Bez širokog spektra znanja i veština svojih članova, tim ne može da organizuje sav posao uspešno.

- Izostanak spoljnog menadžera. Tim ne mora da daje izveštaje menadžeru izvan tima. Članovi tima se brinu o svom budžetu i učinku kroz zajedničko liderstvo.

- Moć da implementiraju svoje odluke. Timovi imaju moć i resurse da implementiraju svoje odluke.

- Koordinacija i kooperacija sa drugim timovima i pojedincima koji su zahvaćeni odlukama tima. Uzevši u obzir činjenicu da su timovi nezavisni i ne moraju formalno da izveštavaju menadžera - svojim akcijama, timovi sami moraju da koordiniraju svoje zadatke i aktivnosti da osiguraju integraciju.

- Timsko vođstvo bazirano na podršci. Liderstvo u timu se često rotira, od jednog člana do drugog, u zavisnosti na eksperti člana u rešavanju određene situacije. Umesto lidera koji govori drugima šta da rade, postavlja ciljeve ili nadgleda učinak, lider $u$ timu se stara da tim ima sve neophodne resurse koji su im neophodni. Podrška podrazumeva olakšavanje timu da dođe do cilja i otklanjanje eventualnih prepreka.

Uspeh tima zavisi od mnogo faktora. Članovi tima moraju da budu pažljivo odabrani tako da se njihova znanja i veštine nadopunjuju. Članovi tima moraju da se fokusiraju i da budu posvećeni cilju tima. Pojedinci dovedeni iz različitih odeljenja kao na primer marketinga proizvodnje moraju da ostave iza sebe način razmišljanja karakterističan za grupu tj za odeljenje i posvete se timu i ostvarenju njihovog cilja. Zadatak tima mora biti kompleksan i opskrbljen svim neophodnim resursima za ostvarenje istog. Takođe tim mora da ima dovoljno autoriteta i moći da uspešno izvrši zadatak. Građenje efektivnog tima je dugotrajan proces i zahteva veštine razvijanja poverenja kao i tehničku potporu. Razvoj poverenja, zajedničke vizije i sposobnosti tima da radi zajedno zavise od više faktora kao što su otvorena komunikacija, integritet, nagrade za kooperaciju, sposobnosti članova tima $i$ njihova posvećenost. Najvažniji od svih faktora jeste taj da članovi tima moraju verovati svom lideru i jedan drugom.

\subsection{Pomaganje timu da postane efektivniji}

lako usavršavanje pojedinih članova tima da budu kompetentniji i efektivniji utiče na sposobnost celokupnog tima da bude produktivniji, često je neophodno dovesti specijalizovanu podršku timu da bi se postigla željena sinergija. Moguće timske aktivnosti namenjene treningu uključuju (Day, Gronn \& Salas, 2004):

- Građenje tima - aktivnosti usmerene ka razjašnjavanju ciljeva tima i uloga svakog člana kao i postavljanje okvira prihvatljive interakcije članova.

- Unakrsni trening da se osigura da svi članovi tima razumeju međusobne zadatke.

- Trening koordinacije sa ciljem da se članovima tima omogući da rade zajedno i poboljšaju komunikaciju i koordinaciju.

- Samokorekcija da se nauče članovi tima da nadgledaju procenjuju svoj učinak i da ispravljaju tj. poboljšavaju svoju komunikaciju sa ostalim članovima.

- Trening samopouzdanja i odlučnosti sa ciljem da se pomogne članovima tima da se izraze na najbolji mogući način kada zahtevaju, daju povratnu informaciju drugom članu i td.

\section{Transakciono liderstvo}

Transakciono liderstvo je bazirano na konceptu razmene između lidera i sledbenika. Lider omogućava sledbenicima neophodne resurse i nagrade u zamenu za motivaciju, produktivnost $i$ efektivno izvršenje zadataka. Ova razmena i koncept obezbeđivanja nagrada za očekivano ponašanje i rezultate, koji se nalazi u srži mnogih teorija motivaciji liderstva kao i menadžmenta. Transakciono liderstvo se može pojaviti u dve forme: koncept potencijalne nagrade i upravljanje po izuzetku (Bass, 1985). 


\subsection{Koncept potencijalne nagrade}

Koncept potencijalne nagrade znači da lider obezbeđuje sledbenike sa obećanom nagradom kada sledbenici ostvare dogovorene ciljeve. Kada se ovom teorijom dobro upravlja potencijalne nagrade su veoma zadovoljavajuće i korisne lideru sledbenicima kao i samoj organizaciji. Ovaj koncept je deo svakog treninga za lidere na kojima se lideri uče da učvrste odgovarajuće ponašanje a obeshrabre neodgovarajuće ponašanje.

\subsection{Menadžment izuzetkom}

Menadžment izuzetkom je stil liderstva gde lider daje malo ili nimalo uputstava zaposlenima $i$ uključuje se samo kada dođe do greške tj. odstupanja od zacrtanog plana. $U$ ovom stilu vođstva lideri su pasivni $i$ indiferentni prema zaposlenima i njihovim zadacima. Lideri se oslanjaju na disciplinu i kaznu kojom koriguju ponašanje zaposlenih. lako je zaposlenima data sloboda da sami odlučuju dok ne pogreše odsustvo podrške i pozitivne radne atmosfere je osetno i stvara veliki pritisak na zaposlene. lako se u retkim slučajevima ovo vođstvo pokazalo kao uspešno veći je broj onih organizacija kod kojih je transakciono vođstvo krivo za minimalan učinak i malu motivaciju. Transakciono liderstvo ne inspiriše zaposlene na duže već samo na kraće staze i daje trenutne rezultate.

\section{Transformaciono liderstvo}

Mnogi naučnici su se bavili proučavanjem liderstva, tako, (Bass, 1985, 1990b; Bennis \& Nanus, 1985 Conger \& Kanungo, 1998) predlažu da u današnje vreme organizacijama je potrebno liderstvo koje inspiriše zaposlene i omogućava im da donesu revolucionarnu promenu. Liderstvo harizmom, je liderstvo u kome lider i njegovi sledbenici stvaraju intenzivnu emotivnu vezu. Rezultat te veze je kompletna lojalnost i poverenje i imitacija lidera od strane sledbenika. Sledbenici su inspirisani da implementiraju liderovu viziju. Jaka lojalnost poštovanje veze koja se stvorila kao i liderove vizije su dobar početak svake revolucionarne promene u organizaciji.

Pored harizme u transformacionom liderstvu veoma je važna liderova sposobnost da stimuliše sledbenike u kreativnom rešavanju problema. Lider i njegovi sledbenici preispituju postojeće vrednosti i pretpostavke i traže nova rešenja (Shin \& Zhou, 2003). Ohrabrujući sledbenike da posmatraju probleme na novi način lideri in inspirišu da rade $i$ šire limit svojih mogućnosti. Veza i harizma koja sledbenike veže za lidera obezbeđuje podršku sprečava sledbenike da se osećaju izolovano. Intelektualna stimulacija podrazumeva jaku komponentu osposobljavanja zaposlenih, njihovo samopouzdanje raste kao i njihove sposobnosti. Transformaciono liderstvo je pokazalo da unapređuje zaposlene i povećava nivo njihove samostalnosti i samopouzdanja.

Još jedan bitan faktor u transformacionom liderstvu je obzirnost. Lider mora svakog svog sledbenika tretirati drugačije (u zavisnosti od toga kakva je ličnost) pravično obezbeđujući svakom pažnju koja mu je potrebna. Kao rezultat sledbenici se osećaju ohrabreni, motivisani, osećaju da napreduju i poboljšava im se učinak (Dvir, Eden, Avolio \& Shamir, 2002). Liderova obzirnost dodatno omogućava da se karakteristike i sposobnosti svakog sledbenika na najbolji način iskoriste za potrebe organizacije.

Harizma, intelektualna stimulacija i obzirnost kada se iskombinuju omogućavaju lideru da započne neophodne promene $u$ organizaciji. Harizma emotivna vezanost prevazilazi emotivne psihološke otpore promeni. Intelektualna stimulacija omogućava nova rešenja i inovacije i unapređuje sposobnosti zaposlenih. Jedinstvena veza koja se stvara između vođe i sledbenika daje dodatan podstrek zaposlenima. Dok transakciono liderstvo podržava održavanje rutine $u$ organizaciji transformaciono liderstvo omogućava adaptaciju na promene u okruženju.

Transformaciono liderstvo je jedno od trenutno najpopularnijih i najistraživanijih teorija o liderstvu. Prema Kelleru (1992) transformaciono liderstvo može da pomogne razvoju grupe i da dovede do veće satisfakcije zaposlenih (Ross \& Offerman, 1997). Druge studije posmatraju faktore koji mogu da ohrabre i vode do transformacionog liderstva uključujući karakteristike sledbenika (Dvir \& Shamir, 2003), kao i stav lidera prema promeni i uticaj nadređenih (Bommer, Rubin, \& Baldwin, 2004). Veliki broj skorašnjih studija proširuje koncept povezujući lične karakteristike za transformaciono liderstvo. $\mathrm{Na}$ primer: jedna studija predlaže da 
ženski transformacioni lideri formiraju jedinstvene veze sa svakim od svojih sledbenika predlažući da je ženama bliži stil vođenja orijentisan na među ljudske odnose (Yammarino, 1997). Žene lideri često ispoljavaju brigu za druge i kooperaciju (Eagly, Karau, \& Makhijani, 1995), osobine koje su povezane sa transformacionim liderstvom. Dodatna istraživanja su neophodna najviše da se utvrdi mera transformacionih i transakcionog liderstva (Yukl, 1999) kao i faktora koji dovode do upotreba transformacionog liderstva od strane samih lidera.

Veoma je lako naučiti lidera o nagradama $i$ kaznama kojima može da modifikuje ponašanje zaposlenih ali je veoma teško naučiti lidera kako da inspiriše svoje sledbenike $\mathrm{i}$ da in intelektualno stimuliše. lako neki naučnici povezuju transformaciono liderstvo sa emotivnom inteligencijom (Gardner \& Stough, 2002), ova povezanost zahteva dodatna istraživanja.

\section{Super i samoliderstvo}

Prema, Charles Manz \&Henry Sims predlažu model liderstva koji uključuje superliderstvo i samoliderstvo svakog člana tima (Manz, 1992) (Manz\&Sims, 1987) (Manz\&Sims, 2001).

Super liderstvo je proces vođenja ljudi tako da oni sami sebe vode. Dok su, Manz i Sims (2001) predložili da umesto koncepta u kome bi se lideri služili strahom kao glavnim oružjem treba da se fokusira na koncept $u$ kome bi lideri nadahnjivali svoje sledbenike da budu posvećeni i ohrabrivali in da sami donose odluke kao i da prihvate odgovornost do te mere da im više lider i nije potreban.

Super liderstvo u okviru tima znači da svi članovi tima postavljaju ciljeve, posmatraju procenjuju, kritikuju, pružaju podršku i nagrađuju jedan drugog kao i same sebe. U takvom okruženju potreba za liderom je smanjena. Članovi tima sami odlučuju šta im je potrebno i kako to da postignu. Povećana upotreba tehnologije, revolucija informacija i nadmoć obrazovanih radnika podržavaju potrebu za super liderstvom. Prema, (Manz \& Neck, 1999) (Manz \& Sims, 2001) super liderstvo podrazumeva razvijanje pozitivnog i motivacionog načina razmišljanja. Pojedinci i timovi traže i razvijaju okruženje koje podržava pozitivnu i motivacionu radnu klimu i način razmišljanja:

- postavljanje ličnih ciljeva - Individue i timovi postavljaju ciljeve i rezultate koje žele da dostignu.

- samoprocena - Članovi tima posmatraju svoj učinak, kao i učinak drugih članova tima $\mathrm{i}$ pružaju povratnu informaciju.

- samonagrađivanje - Članovi tima pružaju podršku i nagrađuju jedni druge za postignute rezultate.

\section{Zaključna razmatranja}

$\mathrm{Na}$ osnovu izloženog, mogu se izvući sledeći zaključci:

- Uloga lidera se menja od uloge glavnokomandujućih do uloge trenera svojih timova.

- Lideri su oni koji brinu o svom timu i pomažu im da ostvare svoje ciljeve pružajući im podršku, instrukcije, resurse, razrešenje konflikta ukoliko do njih dođe.

- Savremeni lideri i dalje ispunjavaju uloge tradicionalnih lidera ali samo kada se to od njih zatraži. Oni se mešaju samo kada je neophodno, pomažu timu obezbeđujući resurse koji su neophodni da se reše problemi i implementiraju rešenja. Centralna aktivnost savremenih lidera jeste da ocene veštine i sposobnosti tima i omoguće im da se nadograde.

- Liderstvo je kreirano od strane tima a zatim iskorišćeno kao resurs ili kapital $u$ ispunjenju zadataka. Kao takvi svi članovi tima dele liderstvo kao funkciju koja timu pomaže da funkcioniše bolje.

Preporuke za ponašanje lidera, bazirane na transformacionom konceptu liderstva, su sledeće:

- Obezbeđivanje jasne vizije.

- Ohrabrivanje kreativnosti kroz unapređenje zaposlenih, nagrada i tolerisanja greški.

- Postavljanje visokih očekivanja i obezbeđivanje podrške. 
Uloga lidera po konceptu superliderstva je da vode zaposlene uče in i omoguće stvaranje super liderstva i potpunog osamostaljivanja zaposlenih.

Super liderstvo nameće pitanja:

- Da li je koncept lidera postao zastareo?

- Šta će se desiti sa liderima i liderstvom kada svi zaposleni postanu samostalni i samodovoljni?

Mnogi menadžeri i organizacioni lideri brinu da će ostati bez posla kada dođe ovo vreme.

Transformaciono liderstvo je pokazalo da unapređuje zaposlene i povećava nivo njihove samostalnosti i samopouzdanja.
Odgovor na ova pitanja je kompleksan i zavisi od lidera kao i specifičnosti same situacije. Neki lideri se osećaju veoma prijatno u timu dok se neki osećaju veoma neprijatno. Lideri koji se osećaju prijatno u timu će se lako prilagoditi promenama koje nastupaju dok će se druga grupa lidera boriti da povrati moć i kontrolu koju su imali.

Jedno je sigurno, promene u funkciji lidera nastupaju velikom brzinom.

\section{Citirani radovi}

Bass, M. (1985). Leadership and performance beyond expectations. New York: Free Press.

Bass, M. (1990b). From transactional to transformational leadership: Learning to share the vision. Organizational Dynamics 18, no. 3: 19-36.

Bennis, W.G., and Nanus, B. (1985). Leaders: The strategies for taking charge. New York: Harper and Row.

Bommer, W. H., Rubin, R. S. and Baldwin T.T. (2004). Setting the stage for effective leadership: Antecedents of transformational leadership behavior. The Leadership Quarterly 15:

Conger, J. A., Kanungo, R. N. (1998). Charismatic leadership in organizations. Thousand Oaks, CA: Sage Publications.

Corderey, J. (2004). Another case of the Emperor's new clothes? Journal of Occupational and Organizational Psychology 77

Day, D.V., Gronn, P., and E. Salas. (2004). Leadership capacity in teams. The Leadership Quarterly 15.

Dvir, T., Eden, D., Avolio, B. J., and Shamir, B. (2002). Impact of transformational leadership on follower development and performance in a field experiment. Academy of Management Journal 45.

Dvir, T., Shamir, B. (2003). Follower development characteristics as predicting transformational leadership: A longitudinal field study. The Leadership Quarterly 14.

Eagly, A. H., Karau, S. J., Makhijani, M.G. (1995). Gender and the effectiveness of leaders: A meta-analysis. Psychological Bulletin 117.

Fisher, K. (1993). Leading self-directed work teams. New York: McGraw-Hill.

Forster,T. (2004). Using delegation as a developmental tool: Methods and benefits. Training Journal May.

Gardner, L., Stough, C. (2002). Examining the relationship between leadership and emotional intelligence in senior level managers. Leadership and Organizational Development Journal 23 (1/2):

Hackman, J. R., Oldham, G. R. 1980. Work redesign. Reading, MA: Addison-Wesley

Keller, R.T. (1992). Transformational leadership and the performance of research and development project groups. Journal of Management 18.

Manz, C. C. (1992). Self-leading work teams: Moving beyond self-management myths. Human Relations 11.

Manz, C. C., and Sims, H. P. Jr. (1987). Leading workers to lead themselves: The external leadership of self-managing work teams. Administrative Science Quarterly 32

Manz C. C., and Sims, Jr. H. P. (2001).The new super leadership: Leading others to lead themselves. San Francisco, CA: Berrett -Koehler Publisher Inc.2001.

Manz, C. C., Neck, C. (1999). Mastering self leadership: Empowering yourself for personal excellence, 2nd edition. Upper Saddle River, NJ: Prentice Hall 
Trmčić S. i dr. Konceptualni okvir - liderstvo

FBIM Transactions Vol.1 No.1 pp. 101 - 110

McClelland, D. C. (1975). Power: The inner experience. New York: Irvington

Nahavandi, A., Aranda, E. (1994). Restructuring teams for the re-engineered organization. Academy of Management Executive 8

Ross, S. M., Offerman, L. R. (1997). Transformational leaders: Measurement of personality attributes and work group performance. Personality and Social Psychology Bulletin 23.

Shin, S. J., Zhou, J. (2003). Transformational leadership, conservation, and creativity: Evidence from Korea. Academy of Management Journal 46.

Swan, K. (2000). Difference is power. Fast Company (July): 258-266.

Truby. M. (2003). Bill Ford Jr. carries on family traditions. The Detroit News. Accessed online at www.detnews.com/2003/specialreport/0306/ 09/f05-186877.htm

Yammarino, F. J., Dubinsky, A. J., Comer, L. B., and Jolson, M. A. (1997). Women and transformational and contingency reward leadership: A multiple-levels-of-analysis perspective. Academy of Management Journal 40.

Yukl, G.A. (1999). An evaluation of conceptual weaknesses in transformational and charismatic leadership theories. The Leadership Quarterly 10(2), 285-305

Datum prve prijave:

19.09.2012.

Datum prihvatanja članka:

26.11.2012.

\section{Kako citirati ovaj rad?}

Style - APA Sixth Edition:

Trmčić, S., Milinković, O., \& Trmčić., M. (2013, 01 15). Konceptualni okvir - liderstvo. (Z. Čekerevac, Ed.) FBIM Transactions, 1(1), 101-110. Retrieved from www.meste.org/fbim/FBIM_1_2013/_11.pdf. doi: 10.12709/fbim.01.01.01.11

Style - Chicago Fifteenth Edition:

Trmčić, Snežana, Ozrislava Milinković, and Marko Trmčić. "Konceptualni okvir - liderstvo." Edited by Zoran Čekerevac. FBIM Transactions (MESTE NVO) 1, no. 1 (01 2013): 101-110.

Style - GOST Name Sort:

Trmčić Snežana, Milinković Ozrislava and Trmčić. Marko Konceptualni okvir - liderstvo [Journal] = Konceptualni okvir - liderstvo // FBIM Transactions / ed. Čekerevac Zoran. - Beograd : MESTE NVO, 01 15, 2013. - 1 : Vol. 1. - pp. 101-110.

\section{Style - Harvard Anglia:}

Trmčić, S., Milinković, O. \& Trmčić., M., 2013. Konceptualni okvir - liderstvo. FBIM Transactions, 15 01, 1(1), pp. 101-110.

Style - ISO 690 Numerical Reference:

Konceptualni okvir - liderstvo. Trmčić, Snežana, Milinković, Ozrislava and Trmčić., Marko. [ed.] Zoran Čekerevac. 1, Beograd : MESTE NVO, 01 15, 2013, FBIM Transactions, Vol. 1, pp. 101-110. 